\title{
三次元個別要素法による数值移動床の一般化 GENERALIZED MOBABLE BED SIMULATOR BY USING 3D DISTINCT ELEMENT METHOD
}

\author{
後藤仁志 ${ }^{1}$ 原田英治 ${ }^{2} \cdot$ 酒井哲郎 $^{3}$ \\ Hitoshi GOTOH, Eiji HARADA and Tetsuo SAKAI
}

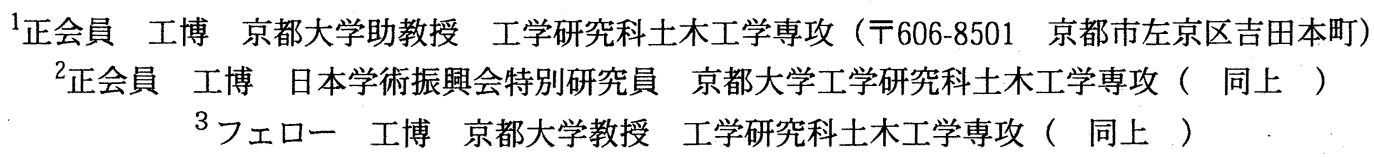

The vertical 2D movable bed simulator, which has been a key tool of the computational mechanics of sediment transport, has a limitation in describing some of details of sediment transport phenomena. Because all of sediment particles have their center of gravity on the same vertical plane, the 2D model cannot describe the effect of the particles existing in an external space of the calculated vertical plane. This limitation of 2D model brings some problems, which comes from a geometrical arrangement of particles, especially on the simulation of grain sorting. The framework of 3D movable bed simulator, which is based on the distinct element method, is shown herein. A dam-up process of sediment body moving on a uniform slope by fixed vertical columns is simulated to show some part of performance of the present model.

Key Words: sediment transport, 3D Movable Bed Simulator, computational mechanics, Distinct Element Method

\section{1. 緒 言}

移動床を微視的に見ると, 『粒』の集合体として の特性が際立って見えてくる.いわゆる『数値移動 床』は，『粒』の集合体としての移動床の本質的特 性である粒子間衝突を直接記述することにより, 計 算力学的な観点からの移動床水理学の進展に貢献し てきた. 言うまでもなく, 移動床の数理モデルを考 える上で最も重要な観点は『粒状体か連続体か』と いうことであり, 従来用いられてきた鉛直二次元個 別要素法を基礎とした数值移動床が『粒状体』とい う移動床の本質を記述するために適切なモデルで あったことには疑念がないと著者らは考えている. 鉛直二次元数值移動床は, 移動床上を運動する saltation 粒子の見かけの反発係数, シートフロー状の運 動を呈する高濃度粒子流の流動機構など, 粒子間衝 突に構造を支配される場において個々の砂粒子の運 動機構に忠実なモデルであり, 均一砂1) は言うまで もなく, 混合砂の分級現象 ${ }^{2)} に$ 対しても，一定の説 明力を発揮してきた.

その一方で, 実現象はあくまで三次元的であり， 現象により忠実にという理想を追及すると三次元モ
デルが必要となる. 三次元化に際してのプログラミ ング的な対応が比較的容易であるにもかかわらず, 個別要素法の三次元化がそれほど活発化しなかった のは, 離散型モデルの宿命とも言うべき計算負荷の 高さに拠るところが大きい. ところが，近年，計算 機の低廉化と高速化が進行し, 比較的短時間の現象 を対象にすれば，数万の粒子を対象とした計算が パーソナルコンピュータでも実行できるようになっ てきた.このような計算環境の変化が，三次元化へ の敷居を急速に低くしつつあるのが現状である.

鉛直二次元数值移動床には, 解析対象面 (鉛直二 次元平面）外部の粒子からの影響を合理的に評価で きないという弱点がある．換言すると，鉛直二次元 では全ての粒子が同一平面内で接触することとなる が，このことと現実との乘離は明らかである．砂粒 子が鉛直二次元平面内に拘束されると運動の自由度 が低くなり, 粒子間衝突の発生頻度が増大し, 結果 として流動抵抗が増大すると考えられる．また，粒 子堆積層に関しても，とりわけ均一粒径では，規則 的で剛な（変形抵抗が大きい）配列が形成され易 く, 粒子層の場所的な粗密にコントラストが付き易 い.このような粒子配列の粗密に原因が求められる 
現象への数值移動床の適用（例えば, 数值移動床に よる砂面初期擾乱の解析（後藤ら ${ }^{31}$ ) ) ) に際して は，粒子配列の不均質性の影響が過大に評価されて いる可能性が懸念される．また，混合粒径では，何 れの粒径階に属する粒子も同一面内接触するという 前提で解析されるが，大粒径の周囲には小粒径の三 次元的な（鉛直面外）接触が存在するはずであり, その影響を適正に評価するには, 三次元モデル が必 要となる.

本研究では，このような認識から，これまで数值 流砂水理学の研究ツールとして用いてきた鉛直二次 元数值移動床を三次元に拡張するための基礎的なフ レームワークを行って, 円柱障害物群による崩壊土 砂流の堰止め過程への適用結果を示す.

\section{2. 個別要素法の三次元表記}

\section{(1) 粒子の運動方程式}

個々の粒子の運動は, 隣接粒子との接触力に起因 する並進および回転の運動方程式

$$
\begin{gathered}
{\left[\begin{array}{c}
\Delta \ddot{x}_{i} \\
\Delta \ddot{y}_{i} \\
\Delta \ddot{z}_{i}
\end{array}\right]=\left[\begin{array}{l}
F_{x i} / M_{i} \\
F_{y i} / M_{i} \\
F_{z i} / M_{i}
\end{array}\right]-\left[\begin{array}{l}
0 \\
g \\
0
\end{array}\right]} \\
{\left[\begin{array}{c}
\Delta \ddot{\phi}_{x i} \\
\Delta \ddot{\phi}_{y i} \\
\Delta \ddot{\phi}_{z i}
\end{array}\right]=\left[\begin{array}{l}
T_{x i} / I_{i} \\
T_{y i} / I_{i} \\
T_{z i} / I_{i}
\end{array}\right]} \\
M_{i}=\frac{\sigma \pi d_{i}^{3}}{6} ; I_{i}=\frac{\sigma \pi d_{i}{ }^{5}}{60}
\end{gathered}
$$

で記述される.ここに， $\left(x_{\mathrm{i}}, y_{\mathrm{i}}, z_{\mathrm{i}}\right),\left(\phi_{\mathrm{xi}}, \phi_{\mathrm{yi}}, \phi_{\mathrm{zi}}\right):$ グロー バル座標系 $(x, y, z)$ 上での粒子 $i$ の位置と回転角, $\left(F_{\mathrm{x}}\right.$, $\left.F_{y}, F_{z}\right):$ グローバル座標系 $(x, y, z)$ 上での粒子間接触 力, $M_{\mathrm{i}}$ : 粒子 $i$ 質量, $\left(T_{\mathrm{x}}, T_{\mathrm{y}}, T_{\mathrm{z}}\right):$ グローバル座標系 $(x, y, z)$ 上での粒子間作用モーメント, $I_{\mathrm{i}}:$ 粒子 $i$ の慣 性モーメント, $g$ : 重力加速度, $\sigma:$ 粒子の密度であ る.

\section{(2) ローカル座標系}

粒子間接触力に関しては, 図-1に示すローカル座 標系 $(\xi, \eta, \zeta)$ に変換して，2 粒子間接平面の法線方 向成分および接平面内 2 成分について，2次元モデ ルと同様にバネ-ダシュポットを配置してモデル化す る. 粒子 $i$ おび功接触している状態を想定する. ローカル座標系の座標軸の定義は以下のようにす る. 粒子 $i$ の中心から粒子 $j$ の中心に向かう方向に $\xi_{\mathrm{i}}$ 軸をとる. $\xi_{\mathrm{i}}$ 軸を法線する 2 粒子間接平面と $x y$ 平面 に平行な任意の平面の交線の中で粒子 $i$ の中心を通る 軸を $\eta_{\mathrm{i}}$ 軸として, これら 2 軸と右手系をなすように

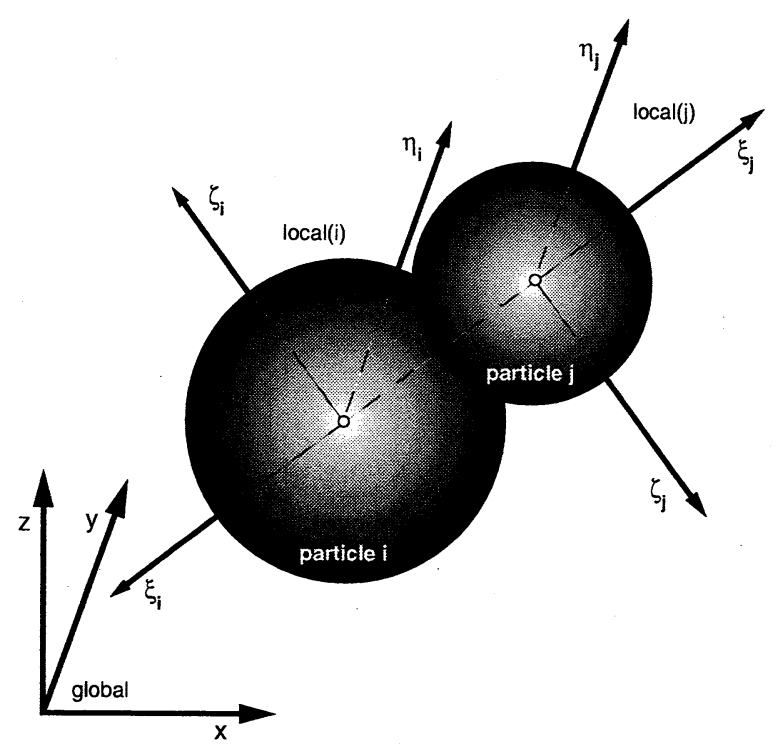

図-1 ローカル座標系

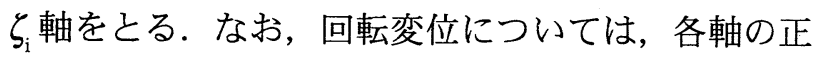
方向に右ネジを回す回転を正と定義する.

2 次元モデルでは粒子間接触力評価のための座標 変換のプロセスも含めた形式で接触力が記述される ことが多いが，3 次元では変換が複雑となるので基 礎式とは分離し，以下のように記述する.

$$
\begin{array}{r}
{\left[\begin{array}{c}
F_{x i} \\
F_{y i} \\
F_{z i}
\end{array}\right]=-\sum_{j}\left[T_{G L}\right]_{i j}^{-1}\left[\begin{array}{c}
F_{\xi} \\
F_{\eta} \\
F_{\zeta}
\end{array}\right]_{i j}} \\
{\left[\begin{array}{c}
T_{x i} \\
T_{y i} \\
T_{z i}
\end{array}\right]=-\sum_{j}\left[T_{G L}\right]_{i j}^{-1}\left[\begin{array}{c}
T_{r} \\
0 \\
0
\end{array}\right]_{i j}} \\
+\frac{d_{i}}{2} \sum_{j}\left[T_{G L}\right]_{i j}^{-1}\left[\begin{array}{c}
0 \\
F_{\zeta} \\
-F_{\eta}
\end{array}\right]_{i j}
\end{array}
$$

ここに, 添え字は各座標軸方向の成分を意味し, 座 標変換行列 $T_{\mathrm{GL}}$ は, $y_{\mathrm{j}}>y_{\mathrm{i}}$ and $\left(x_{\mathrm{j}} \neq x_{\mathrm{i}}\right.$ or $\left.z_{\mathrm{j}} \neq z_{\mathrm{i}}\right)$ に対して,

$$
\left[T_{G L}\right]_{i j}=\left[\begin{array}{ccc}
l_{i} & m_{i} & n_{i} \\
\frac{-m_{i}}{\sqrt{l_{i}^{2}+m_{i}^{2}}} & \frac{l_{i}}{\sqrt{l_{i}^{2}+m_{i}^{2}}} & 0 \\
\frac{-l_{i} n_{i}}{\sqrt{l_{i}^{2}+m_{i}^{2}}} & \frac{-m_{i} n_{i}}{\sqrt{l_{i}^{2}+m_{i}^{2}}} & \sqrt{l_{i}^{2}+m_{i}^{2}}
\end{array}\right]
$$

$y_{\mathrm{j}}<y_{\mathrm{i}}$ and $\left(x_{\mathrm{j}} \neq x_{\mathrm{i}}\right.$ or $\left.z_{\mathrm{j}} \neq z_{\mathrm{i}}\right)$ に対して, 
$\left[T_{G L}\right]_{i j}=\left[\begin{array}{ccc}l_{i} & m_{i} & n_{i} \\ \frac{m_{i}}{\sqrt{l_{i}^{2}+m_{i}^{2}}} & \frac{-l_{i}}{\sqrt{l_{i}^{2}+m_{i}^{2}}} & 0 \\ \frac{l_{i} n_{i}}{\sqrt{l_{i}^{2}+m_{i}^{2}}} & \frac{m_{i} n_{i}}{\sqrt{l_{i}^{2}+m_{i}^{2}}} & -\sqrt{l_{i}^{2}+m_{i}^{2}}\end{array}\right]$

と書ける.ここに,

$$
\left[\begin{array}{c}
l_{i} \\
m_{i} \\
n_{i}
\end{array}\right]=\left[\begin{array}{c}
\frac{x_{j}-x_{i}}{R_{i j}} \\
\frac{y_{j}-y_{i}}{R_{i j}} \\
\frac{z_{j}-z_{i}}{R_{i j}}
\end{array}\right]
$$

であり, $x_{\mathrm{j}}=x_{\mathrm{i}}$ and $z_{\mathrm{j}}=z_{\mathrm{i}}$ については,

$$
\begin{aligned}
& {\left[T_{G L}\right]_{i j}=\left[\begin{array}{ccc}
0 & 0 & -1 \\
0 & 1 & 0 \\
1 & 0 & 0
\end{array}\right] \text { for } z_{i}<z_{j}} \\
& {\left[T_{G L}\right]_{i j}=\left[\begin{array}{ccc}
0 & 0 & 1 \\
0 & 1 & 0 \\
-1 & 0 & 0
\end{array}\right] \text { for } z_{i}>z_{j}}
\end{aligned}
$$

と定義する.

\section{(3) 接触判定および接触力評価}

粒子の接触判定条件は, 粒子 $i, j$ の粒径と中心間距 離を参照して,

$$
\begin{gathered}
R_{i j} \leq \frac{d_{i}+d_{j}}{2} \\
R_{i j}=\sqrt{\left(x_{i}-x_{j}\right)^{2}+\left(y_{i}-y_{j}\right)^{2}+\left(z_{i}-z_{j}\right)^{2}}
\end{gathered}
$$

\section{によって行う.}

粒子間作用力の算定には変位および回転増分が変 数として導入されている. グローバル座標系におけ る微少時間 $\Delta t$ 間の任意の粒子 $i$ の並進増分, 回転変 位増分 $\left(\Delta x_{\mathrm{i}}, \Delta y_{\mathrm{i}}, \Delta z_{\mathrm{i}}\right)$ および $\left(\Delta \phi_{\mathrm{xi}}, \Delta \phi_{\mathrm{yi}}, \Delta \phi_{\mathrm{zi}}\right)$ は，

$$
\begin{array}{r}
{\left[\begin{array}{c}
\Delta \xi_{i} \\
\Delta \eta_{i} \\
\Delta \zeta_{i}
\end{array}\right]=\left[T_{G L}\right]_{i j}\left[\begin{array}{c}
\Delta x_{i}-\Delta x_{j} \\
\Delta y_{i}-\Delta y_{j} \\
\Delta z_{i}-\Delta z_{j}
\end{array}\right]} \\
+\left[\begin{array}{cc}
0 & 0 \\
\Delta \phi_{\zeta i} & \Delta \phi_{\zeta j} \\
-\Delta \phi_{\eta i} & -\Delta \phi_{\eta j}
\end{array}\right]\left[\begin{array}{c}
\frac{d_{i}}{2} \\
\frac{d_{j}}{2}
\end{array}\right]
\end{array}
$$

$$
\left[\begin{array}{c}
\Delta \phi_{\xi i} \\
\Delta \phi_{\eta i} \\
\Delta \phi_{\zeta i}
\end{array}\right]=\left[T_{G L}\right]_{i j}\left[\begin{array}{c}
\Delta \phi_{x i} \\
\Delta \phi_{y i} \\
\Delta \phi_{z i}
\end{array}\right]
$$

によってローカル座標系に変換される.

要素間の接触状態については以下のように取り扱う. 要素 $i, j$ の接触面には, 法線（锗）方向および接平 面（ $\eta$ 軸および軸）方向に弾性スプリング（バネ定数 $k_{\mathrm{n}}, k_{\mathrm{s}}$ ) および粘性ダッシュポット（粘性定数 $c_{\mathrm{n}}, c_{\mathrm{s}}$ ) を 配置して相互作用を表現する. なお，接触面における 法線（軸）まわりの回転に対しては, 回転角と並進 変位の間にアナロジーを想定して, 弾性スプリング (バ ネ定数 $k_{\mathrm{r}}$ ) および粘性ダッシュポット（粘性定数 $c_{\mathrm{r}}$ ) を配置している. 法線方向力 $\left(F_{\xi}\right)$ と接線方向力 $\left(F_{\eta}\right.$ ,$\left.F_{\zeta}\right)$ およびねじりモーメント $\left(T_{\mathrm{r}}\right)$ は, 以下のよう に評価される。

$$
\begin{aligned}
& \left.\begin{array}{l}
F_{\xi}(t)=e_{n}(t)+d_{n}(t) \\
e_{n}(t)=e_{n}(t-\Delta t)+k_{n} \cdot \Delta \xi_{i} \\
d_{n}(t)=c_{n} \cdot \Delta \dot{\xi}_{i}
\end{array}\right\} \\
& \left.\begin{array}{l}
F_{\eta}(t)=e_{s \eta}(t)+d_{s \eta}(t) \\
e_{s \eta}(t)=e_{s \eta}(t-\Delta t)+k_{s} \cdot \Delta \eta_{i} \\
d_{s \eta}(t)=c_{s} \cdot \Delta \dot{\eta}_{i}
\end{array}\right\} \\
& \left.\begin{array}{l}
F_{\zeta}(t)=e_{s \zeta}(t)+d_{s \zeta}(t) \\
e_{s \zeta}(t)=e_{s \zeta}(t-\Delta t)+k_{s} \cdot \Delta \zeta_{i} \\
d_{s \zeta}(t)=c_{s} \cdot \Delta \dot{\zeta}_{i}
\end{array}\right\} \\
& \left.\begin{array}{l}
T_{r}(t)=e_{r}(t)+d_{r}(t) \\
e_{r}(t)=e_{r}(t-\Delta t)+k_{r} \cdot\left(d_{i} / 2\right)^{2} \cdot \Delta \Phi \\
d_{r}(t)=c_{r} \cdot\left(d_{i} / 2\right)^{2} \cdot \Delta \dot{\Phi}
\end{array}\right\} \\
& \Delta \Phi=\left[l_{i}, \quad m_{i}, n_{i}\right]\left[\begin{array}{l}
\Delta \phi_{x i}-\Delta \phi_{x j} \\
\Delta \phi_{y i}-\Delta \phi_{y j} \\
\Delta \phi_{z i}-\Delta \phi_{z j}
\end{array}\right]
\end{aligned}
$$

ここに, $e_{\mathrm{n}}, e_{\mathrm{s}^{\prime}}, e_{\mathrm{r}}$ : 法線, 接平面および回転方向のバ ネによる抗力, $d_{\mathrm{n}}, d_{\mathrm{s}^{\prime}} d_{\mathrm{r}}$ : 法線, 接平面および回転方 向のダッシュポットによる抗力である. なお，式中の 「」」は洔間微分を示し,

$$
\Delta \dot{\xi} \equiv \Delta \xi / \Delta t
$$

で定義される．また，非粘着性材料を対象とすること から, 法線（軸）方向に引つ張りに抵抗しないジョ 
イント

$$
F_{\xi}(t)=0 \quad \text { when } e_{n}(t)<0
$$

接平面（ $\eta$ 軸および軸）方向に一定の限界を越える力 が作用すると滑動するジョイント

$$
\begin{array}{r}
F_{\eta}(t)=\mu \cdot \operatorname{SIGN}\left(e_{n}(t), e_{s}(t)\right) \\
\text { when }\left|e_{s}(t)\right|>\mu \cdot e_{n}(t) \\
F_{\zeta}(t)=\mu \cdot \operatorname{SIGN}\left(e_{n}(t), e_{s}(t)\right) \\
\text { when }\left|e_{s}(t)\right|>\mu \cdot e_{n}(t)
\end{array}
$$

をそれぞれ配置したここに， $\mu$ : 接触点における動 摩擦係数 $(\mu=0.577), \operatorname{SIGN}(a, b)$ は $|a|$ に $b$ の符 合を付けることを意味する. 以上のモデルは, 基本的 には, 吉田ら ${ }^{4)}$, 重松ら ${ }^{5)}$ と同様のものであるが, 基礎式や粒子間接触力評価等のディテールに相違があ るので, モデルの構造を厳密に示すために, 省略せず に記述した。

モデル定数は, 個別要素法で用いる計算時間ステッ プ $\Delta t=1.0 \times 10^{-3}$ (s) に対して, 後藤ら ${ }^{6)}$ の設定法を 用いて， $k_{\mathrm{n}}=3.80 \times 10^{6}(\mathrm{~N} / \mathrm{m}) ， k_{\mathrm{s}}=1.46 \times 10^{6}(\mathrm{~N} /$ $\mathrm{m}), \eta_{\mathrm{n}}=5.14 \times 10^{4}(\mathrm{Ns} / \mathrm{m}), \eta_{\mathrm{s}}=3.19 \times 10^{4}(\mathrm{Ns} / \mathrm{m})$ のように設定した. なお，本シミュレーションでは， 吉田ら ${ }^{4)}$ と同様に, 回転方向のバネ定数 $k_{\mathrm{r}}$ および粘 性定数 $c_{\mathrm{r}}$ はゼロとしている.

\section{3. 崩壊土砂の堰止め過程の解析}

\section{(1) 計算領域および計算条件}

開発したコードの性能確認のため，一様斜面上に 円柱状の障害物を配置し, 上方から崩壊土砂を流動 させて, 障害物による堰止め・流動阻止の過程を計 算した．計算領域を図-2に示す，水平面に接続した 勾配 30 度の一様斜面（全長 $98.0 \mathrm{~m}$ ）の上端部に斜面 長 $20.0 \mathrm{~m}$ にわたって配置した土砂層（初期層厚 約 $10.0 \mathrm{~m} ）$ の崩壊・流下のプロセスを追跡する，斜面に は20.0mの側壁が設けられているが, 計算結果の表示 の際には土塊の運動を見易くするために側壁を取り 去っている. なお，本稿では含有水の影響を考慮し ていないので, 乾燥粒状体の流動過程を訳算してい ることとなる.

斜面の下端より斜面に沿って $18.0 \mathrm{~m}$ 登つた地点に は, 円柱群が設置されており, 流下してくる土砂層 が円柱群に堰止められる過程が計算される. 土砂層 は混合粒径であり, 粒径 $1.0 \mathrm{~m}, 0.75 \mathrm{~m}, 0.5 \mathrm{~m}$ の 3 種の粒 子が，1:3:6の比率で一様に混合されるようにランダ ムにパッキングを行って個々の粒子の初期配置を決 定している. 土砂層構成粒子数は約 4,000 個, 固定壁

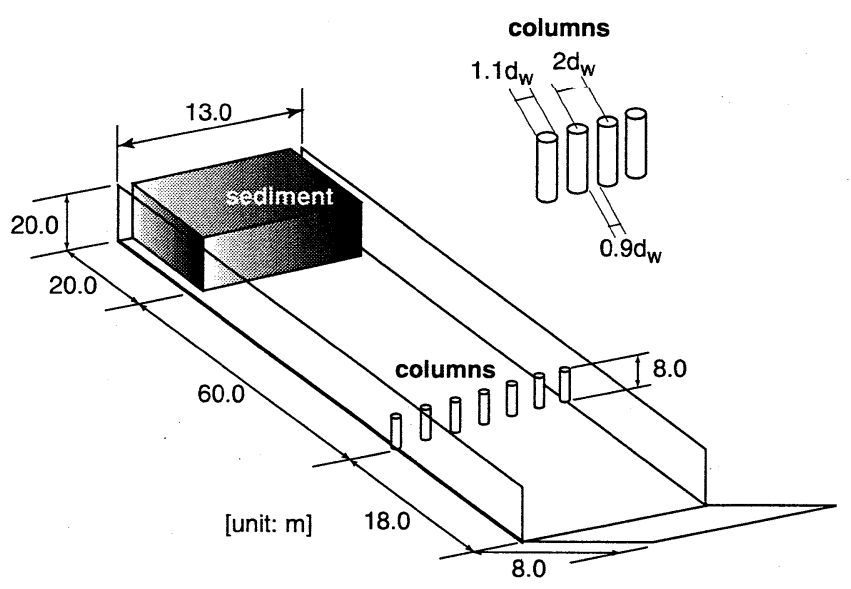

図-2 計算領域

（円柱を含む）粒子数は2,900個で, 総粒子数6,900個 となっている. 円柱群については, 最大粒径 $1.0 \mathrm{~m}$ $\left(=d_{\mathrm{w}}\right)$ よりやや大きい粒径 $1.1 \mathrm{~m}$ の粒子を積み重ねて構 成し, 円柱は $2.0 \mathrm{~m}\left(=2 d_{\mathrm{w}}\right)$ 間隔で配置したので, 円柱 間間隙は $0.9 \mathrm{~m}\left(=0.9 d_{\mathrm{w}}\right)$ となり, 最大粒径のみが円柱間 を通過できない。ささに，斜面は最大粒径と同一の サイズの粒子を規則配列して構成しており, 最大粒 径程度の凹凸を有する粗面である.

\section{(2) 円柱群による堰止め過程}

図-3 は, 円柱群による崩壊土砂の堰止め過程を斜 め上方から俯瞰したものであり, 図-4 は, 図-3 と同 様の瞬間を円柱直下流正面から眺めたものである. 何れの図においても, 縦方向の 4 枚のスナップショッ トは, 土砂層が円柱群に到達した瞬間（時刻 $t=0.0 \mathrm{~s}$ とする）およびその後の時刻 $t=1.0,2.0,4.0 \mathrm{~s}$ の各時 刻における状態を示している。

側壁近傍は粒子の移動が拘束されるので低速領域 が生じ, 側壁から離れるにしたがって粒子の平均移 動速度が増加することとなる.このため粒子が斜面 中央へと集中して粒子層表面が盛り上がり, 粒子層 の横断面が蒲鉾型を呈する様子が示されている.

円柱群に堰止められた最大粒径に阻まれて, 他の 粒径も大部分が円柱群の地点で停止し, 円柱間隙か ら漏れ出す小粒径は僅かである。このケースでは,

円柱高さと比較して土砂層厚が大きいので, 土砂層 上部の粒子群は円柱群上を乗り越えて下流側に到達 する. そのため円柱群を乗り越える粒子の中に最大 粒径が少なからず存在する. 円柱群の乗り越えは, 斜面中央付近で顕著で, 先に述べたような粒子運動 特性（蒲鉾型の横断面）を裏付けている.

計算力学的な方法論の長所の一つは, 現地等では 観測自体が不可能な（ビデオカメラの設置ができな い）場所からも土砂層の流動特性を見ることができ る点である. 図-4 は，その一例を示していると言え 

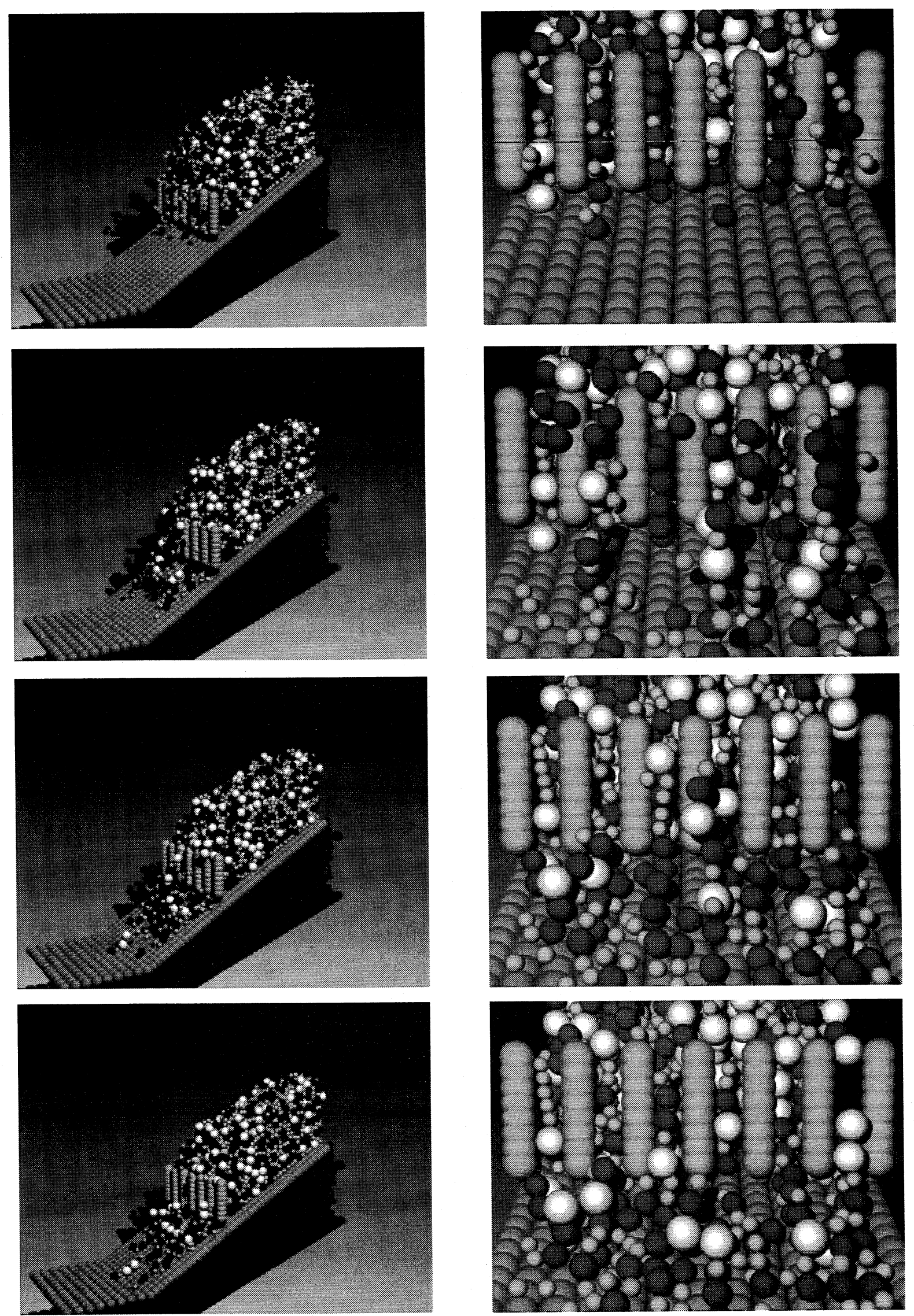

図-3＼cjkstart崩壊土砂の堰止め過程

図-4 崩壊土砂の堰止め過程（クーローズアップ） 

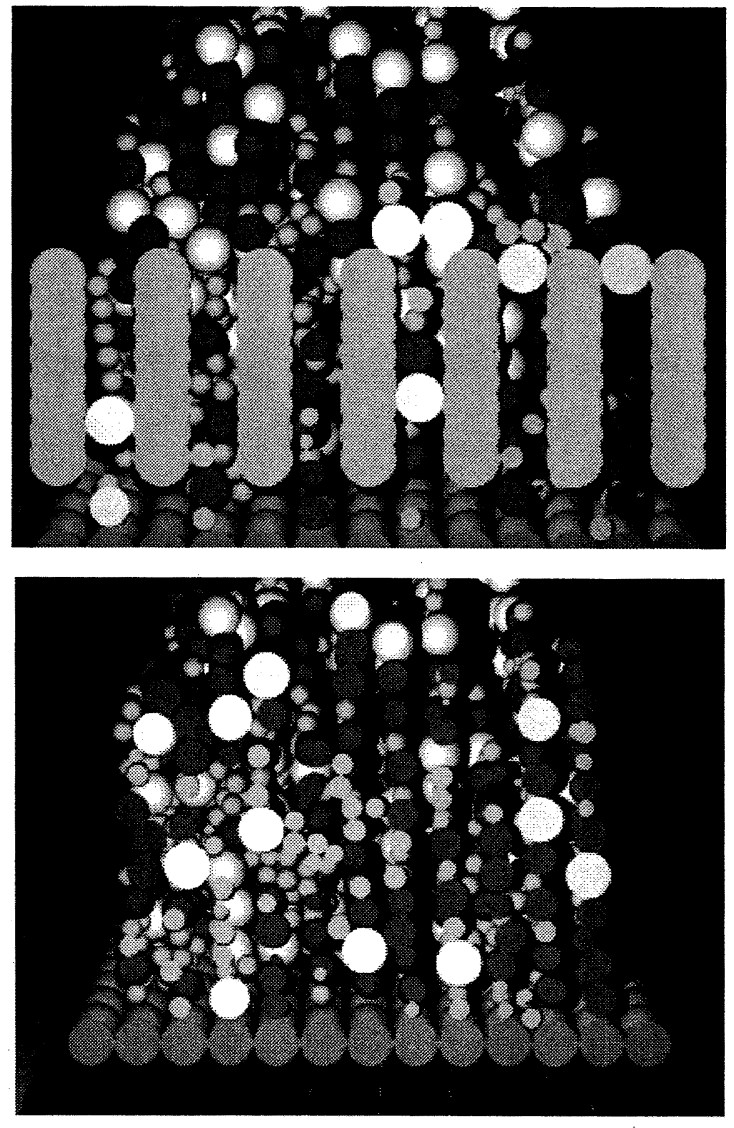

図-5 土砂層横断面

る.土砂流フロントが円柱障害物を乗り越えて氾濫 する様子が, 臨場感ある画像で示されている. さら に，大粒子による閉塞の状態についても詳細を伺い 知ることができる. 時刻 $t=2.0 \mathrm{~s}$ （上から 3 枚目）の右 から1番目と2番目の円柱および2番目と3番目の円柱 に上端付近に2個の大粒子が挟まって停止している. 右から3番目と4番目の円柱の中ほどおよび左端とそ (右側の円柱の足下付近の間隙にも大粒子が挟まっ ている.これらの大粒子の捕捉は閉塞域の拡大の きっかけとなる．例えば，右から2番目と3番目の円 柱に上端付近に捕捉された大粒子は，その下方の大 粒子の運動を妨げて下方に閉塞域を拡大させてい く.この大粒子の下方では, 大粒子と中粒子が支え 合って小アーチを形成し, 閉塞が進行していること が分かる（時刻 $t=2.0,4.0 \mathrm{~s}$ 参照）。

\section{(3) 土砂層の内部特性の推定}

図-4 は観測機材の損傷を覚悟すれば撮影可能かも 知れないが, 観測や水理実験で見ることがさらに困 難な状況も計算力学的な方法論なら容易に見ること ができる. 図-5 は，図-3 および図-4 の時刻 $t=4.0 \mathrm{~s}$ の 瞬間における土砂層の横断面を示している. 上部の 図は，円柱群の鉛直軸を通る断面で切断して上流側 を眺めたもの, 下部の図は, 円柱群から斜面方向に 大粒子の粒径の6倍上流の地点で鉛直方向に切断した
断面の状態を示している.これらの図は光源を手前 に設置した状態で描かれているので, 切断面が高輝 度（薄色に発色すること）となる. 図-4に見られた 大粒子の捕捉状況がより鮮明に表示されているのが 分かる.

流動していない地盤なら地盤探査手法を駆使して 掘削せずに内部構造を推定できるが, 流動を伴う場 合に刻々と変化する土砂層内部の構造を推定する方 法は見当たらない. 時刻 $t=4.0 \mathrm{~s}$ の斜面中央の横断面 図（図-5 の下の図）では，最大粒径の表層付近への 偏在化は流下時間の不足のためか明膫には確認でき ないが，さらに計算領域を大きく取って流下時間を 充分に確保すれば, 逆グレイディングのプロセスを 詳細に把握することも視野に入ってくる.

\section{4. 結 語}

本研究では, 著者らの粒子コードを三次元に拡張 し，円柱障害物群による崩壊土砂流の堰止め過程へ の適用を試みた。計算結果は，斜面中央への土砂の 集中等の三次元性を示し，二次元モデルでは再現不 可能な特性を探るツールとしての三次元数值移動床 の可能性に大いなる示唆を与えるものであった.

ここでは, 計算結果のスナップショットを通し て，主として定性的な考察を加えるに留まっている が, 定量面での検証も行う必要がある. 横断面方向 の平均粒子移動速度や各鉛直断面間の粒子交換の発 生頻度など, 3 次元性が重要となる局面に関して計 算デー夕を整理し，2 次元モデルが十分に機能する 現象と 3 次元モデルでなければ説明できない現象の 区分を明確化することが肝要であると考えている.

\section{参考文献}

1) 後藤仁志・酒井哲郎 : 表層せん断を受ける砂層の動的 挙動の数值解析, 土木学会論文集, 第521号/II-32, pp.101-112, 1995.

2) 原田英治・後藤仁志・酒井哲郎・羽間義照 : 混合粒径 流砂の動的粗粒化過程の数値解析, 水工学論文集, 第 45巻, pp.655-660, 2001.

3）後藤仁志・原田英治・酒井哲郎 : 移動床における砂粒 子間干渉による砂面擾乱の発生, 水工学論文集, 第45 巻, pp.637-642, 2001.

4) 吉田 博・枅谷 浩・今井和昭 : 個別要素法による敷 砂上への落石の衝撃特性に関する解析, 土木学会論文 集, 第392号, pp.297-306, 1988.

5) 重松孝昌・小田一紀・田野雅彦・廣瀬真由 : 個別要素 法による水中沈降粒子群の 3 次元挙動に関する研究, 海岸工学論文集, 第47巻, pp. 996-1000, 2000.

6) 後藤仁志・原田英治・酒井哲郎 : 数値移動床による混 合粒径流砂の流送過程のシミュレーション, 水工学論 文集，第44巻, pp.665-670, 2000.

(2001. 10.1受付) 